\title{
Extremely Low HDL Cholesterol and Increased LDL Cholesterol Induced by the use of Anabolic Steroids in a Body Builder: A Case Study
}

\author{
Min Li and Simon W Rabkin* \\ Department of Medicine, Division of Cardiology, University of British Columbia, Canada
}

*Corresponding author: Dr. Simon Rabkin, MD, FRCPC, FCCS, FESC, FACC, Department of Medicine, Division of Cardiology, University of British Columbia, $9^{\text {th }}$ Floor 2775 Laurel St., Vancouver, B.C., Canada, Tel: (604)-875-5847, Fax: (604)-8755849

\begin{abstract}
Purpose: The objective was to report on the effect of repeated usage of anabolic steroids on LDL and HDL cholesterol.

Results: A man engaged in body building repeatedly used anabolic steroids over a 5-year period. His initial lipids were $\mathrm{HDL}-\mathrm{C}$ of $0.4 \mathrm{mmol} / \mathrm{L}$ and LDL-C of $4.6 \mathrm{mmol} / \mathrm{L}$. After 10 weeks of discontinuation of anabolic steroid, his HDL-C markedly increased to $1.0 \mathrm{mmol} / \mathrm{L}$ and LDL-C was reduced to normal at $3.3 \mathrm{mmol} / \mathrm{L}$. In the subsequent follow-up visits, he resumed anabolic steroid use several times with the lowest levels of HDL-C of 0.2-0.1 mmol/L accompanied by the highest levels of LDL-C at $5.8-6.5 \mathrm{mmol} / \mathrm{L}$. This represented a $100 \%$ increase in LDL and a $90 \%$ reduction in HDL cholesterol. High LDL-C is universally accepted to be linked to atherosclerosis and low HDL-C is a risk factor for cardiovascular disease.

Conclusion: The repeated usage of the anabolic steroids proves the causative effect of anabolic steroids on lipid metabolism producing serum lipids in a range compatible with an increased risk of cardiovascular events.
\end{abstract}

\section{Keywords}

Anabolic steroids, Lipid metabolism, Atherosclerosis, Cardiovascular risk

\section{Learning Points}

- Use of anabolic steroids significantly decreases HDL-C (> 90\%) and increases LDL-C ( 50\%).

- Lipid effects from anabolic steroid use are reversible. HDL-C and LDL-C were normalized 2.5 to 4 months after discontinuation of their usage.

- Reinstitution of anabolic steroids repeatedly produced these adverse effects on lipids.

- The key management of anabolic steroid-induced dyslipidemia is education on the adverse effects of anabolic steroids on the cardiovascular system.

\section{Introduction}

Anabolic steroids are banned substances in competitive sports because they are an exogenous method for performance enhancement in sports that require increased muscle mass or strength. However, these agents are still used by certain athletes who wish to accelerate the increase skeletal muscle mass with exercise [1]. The adverse effect of anabolic steroids on High-Density Lipoprotein Cholesterol (HDL-C) and Low-Density Lipoprotein Cholesterol (LDL-C) has been explored in case control studies comparing those using or not using anabolic steroids or by evaluating serum lipids before and after a course of anabolic steroids [26]. In practice, users of anabolic steroids have programs of repetitive use of these agents. Such usage, to our knowledge has not been studied. In this report, a detailed evaluation of use, cessation and repeated use of anabolic steroids on serum lipids in one individual is presented.

\section{Case}

A 35-year-old man was referred for the management

Citation: Li M, Rabkin SW (2018) Extremely Low HDL Cholesterol and Increased LDL Cholesterol Induced by the use of Anabolic Steroids in a Body Builder: A Case Study. Int J Sports Exerc Med 4:109. doi.org/10.23937/2469-5718/1510109

Accepted: November 27, 2018; Published: November 29, 2018

Copyright: (C) $2018 \mathrm{Li} \mathrm{M}$, et al. This is an open-access article distributed under the terms of the Creative Commons Attribution License, which permits unrestricted use, distribution, and reproduction in any medium, provided the original author and source are credited. 
of dyslipidemia. His past medical history included hypertensive renal disease (CKD stage 3 ) and fatty liver. His baseline lipid profile revealed an HDL-C of 0.4 $\mathrm{mmol} / \mathrm{L}, \mathrm{LDL}-\mathrm{C}$ of $4.6 \mathrm{mmol} / \mathrm{L}$, and Triglycerides (TG) of $1.2 \mathrm{mmol} / \mathrm{L}$. The liver function tests were normal, and the kidney function tests showed increased serum level of creatinine at $152 \mathrm{mmol} / \mathrm{L}$ and an estimated Glomerular Filtration Rate (eGFR) of $46 \mathrm{~mL} / \mathrm{min} / 1.73$ $\mathrm{m}^{2}$. He had no known history of coronary artery or peripheral artery disease. He had hypertension since age 28 , which had been treated with ramipril. He was a lifelong non-smoker and his 10-year Framingham risk score was calculated as $12 \%$. However, he acknowledged the use (self-administration) of anabolic steroids to increase muscle mass as he was a professional body builder. His anabolic steroid regime consisted of intramuscular injections every 4 to 6 weeks of $100 \mathrm{mg}$ Nandrolone (19-nortestosterone), $100 \mathrm{mg}$ Trenbolone (17ß-Hydroxyestra-4,9,11-triene-3-one), $250 \mathrm{mg}$ of Deca Durabolin (19-Nortestosterone), and $100 \mathrm{mg}$ Susranon (which consists of testosterone propionate, testosterone phenylpropionate, testosterone isocaproate, and testosterone decanoate). We encouraged him to stop the use of anabolic steroids and to start a strategy of weight reduction and healthy diet as well as an aerobic exercise program, at his initial visit in our clinic.

After 10 weeks of discontinuation of steroid use, he had noticeable improvement in his overall lipids.
His HDL-C markedly increased to the normal range at $1.0 \mathrm{mmol} / \mathrm{L}$, and his LDL-C was found to be $3.3 \mathrm{mmol} / \mathrm{L}$ (Figure 1). Almost, one year later, his HDL-C was 0.4 $\mathrm{mmol} / \mathrm{L}$ and his LDL-C increased to $5.8 \mathrm{mmol} / \mathrm{L}$. He acknowledged the resumption of steroids and addition of herbal supplements. He stopped the use of anabolic steroids and herbal medication and resumed his aerobic exercise. His lipids significantly improved after 3 months, and his HDL-C and LDL-C were within normal ranges at $1.1 \mathrm{mmol} / \mathrm{L}$ and $3.2 \mathrm{mmol} / \mathrm{L}$, respectively. This lipid improvement continued for 6 months until he had a fractured arm and resumed the use of anabolic steroids but not the herbal supplements. At this point, his HDL-C was suppressed at the level of $0.7 \mathrm{mmol} / \mathrm{L}$. Eight month later, his lipid measurements showed the HDL-C was $0.2 \mathrm{mmol} / \mathrm{L}$ and the LDL-C was $6.5 \mathrm{mmol} / \mathrm{L}$. He did less physical activities, increased his meat consumption, gained $6 \mathrm{~kg}$ in weight, and resumed anabolic steroids 'because of injuries'. The importance of making appropriate changes in his diet and exercise program and the avoidance of steroid use was reinforced. Four months later, he was no longer on steroids, his lipids showed dramatic improvement with an HDL-C of 0.8 $\mathrm{mmol} / \mathrm{L}$. Interestingly, his LDL-C remained elevated at $5.0 \mathrm{mmol} / \mathrm{L}$, highly clinically significant, but not as high as the previous value of $6.5 \mathrm{mmol} / \mathrm{L}$.

Over the course of time he resumed steroids and after clinic visits, we convinced to discontinue their

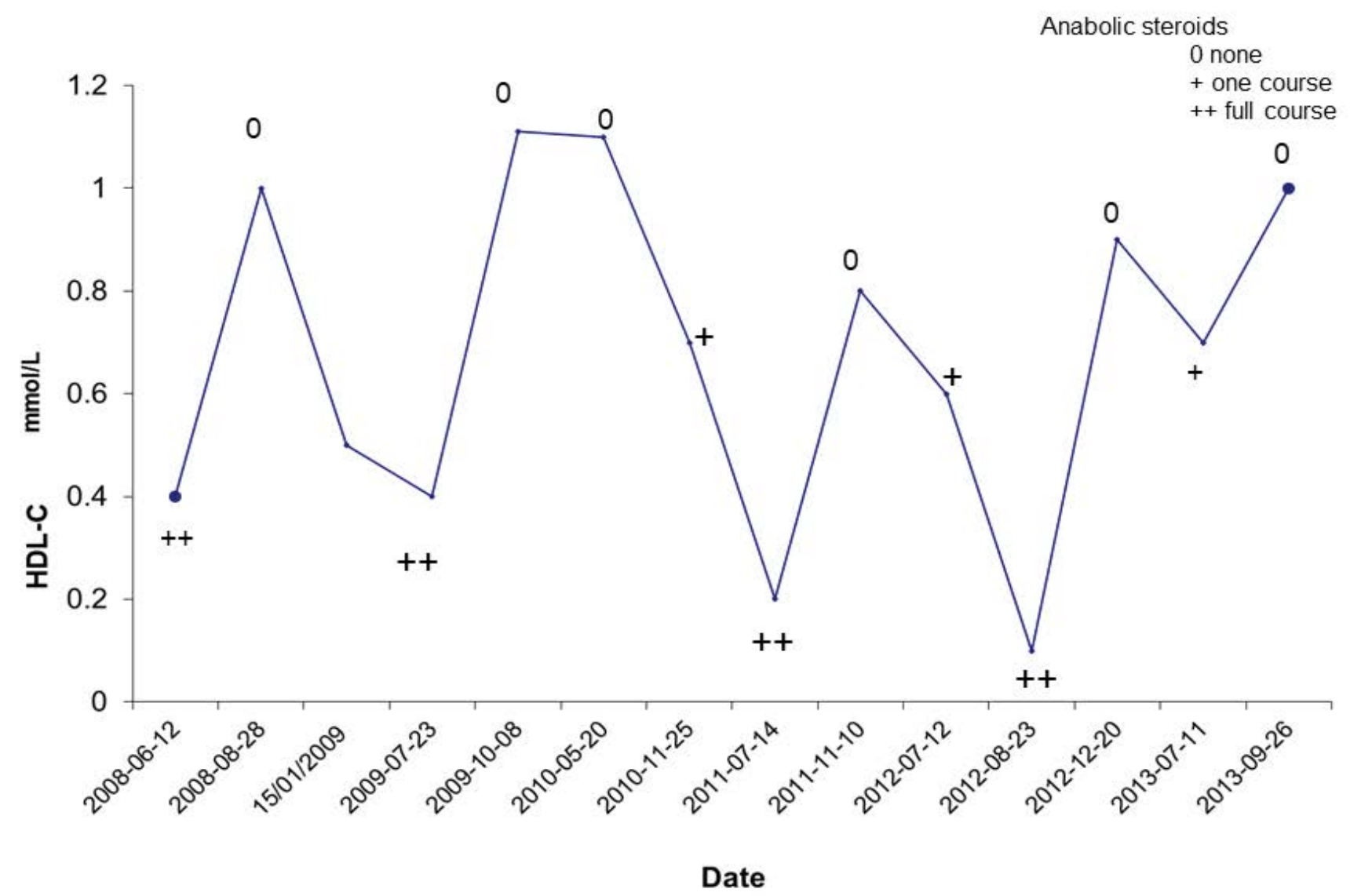

Figure 1: Shows the lipid values over time with the periods of anabolic steroid administration. The key shows the times when he was not taking anabolic steroids $(0)$, had just begun a cycle $(+)$ or had completed a cycle $(++)$ of anabolic steroid usage. 
usage. The effect of repeated usage of anabolic steroids to adversely affect serum lipids was noted (Figure 1 ). His lowest $\mathrm{HDL}$ cholesterol was $<0.1 \mathrm{mmol} / \mathrm{L}$ at the time his Apo $\mathrm{A} 1$ was $0.14 \mathrm{~g} / \mathrm{L}$.

\section{Discussion}

Anabolic steroids are synthetic derivatives of testosterone and are used widely by some athletes to improve their physical performance [1]. The use of anabolic steroids is associated with adverse effects including increased cardiovascular risk [7]. Cross sectional data support the contention that the use of anabolic steroids in athletes can significantly reduce HDL-C and increase LDL-C concentrations in blood [2] and may be related to acute myocardial infarction [8] or ischemic stroke [9]. There is, however, little long-term data on repetitive usage of anabolic steroids and its effect on lipids.

In this report, we describe a 5 years' follow-up case of an individual in whom the levels of HDL-C and LDL-C were dramatically affected by using anabolic steroids. He was a body builder (weight lifter) and initially presented with low HDL-C and high LDL-C levels with a history of the use of steroids, which suggested that his dyslipidemia may be the effects of anabolic steroid use. Repeated cycles of discontinuation and reintroduction of anabolic steroids allowed us to conclude that anabolic steroid usage adversely affected LDL and HDL cholesterol.

After his initial discontinuation of the steroids, 10 weeks later, his HDL-C and LDL-C were markedly improved to the normal range (Figure 1 ). This result indicated that the low HDL-C was most likely related to his steroid use, rather than a genetic factor as his HDL-C was normalized after he stopped the steroid use. It has been reported that while the effect of anabolic steroids on HDL-C concentrations are reversible $[5,10]$, the levels of HDL-C normalize after 5 months following discontinuation [5]. In our case, it took only approximate 2.5 months for HDL-C at $0.4 \mathrm{mmol} / \mathrm{L}$ to go back to normal value at $1.0 \mathrm{mmol} / \mathrm{L}$ after stopping the use of the steroid; approximately half of the time as compared to data in the above report [5]. In the subsequent 5 years' follow-up, the patient resumed the use of anabolic steroids several times due to his sports interest and his contention that it improved his medical conditions. His HDL-C showed dramatic responses to the use of steroids. Each use of the steroids produced a dramatic effect on his lipid profile which exhibited corresponding changes, especially the marked decrease in HDL-C levels. His lowest HDL-C level reached $0.1 \mathrm{mmol} / \mathrm{L}$ (Apo A1 of 0.14 $\mathrm{g} / \mathrm{L}$ ); a reduction of more than $90 \%$ compared with his normal HDL-C levels, showing that he was very sensitive to the use of steroids. From this point, he started to stop the use of anabolic steroids and his HDL-C levels gradually increased to the nearly normal range of 0.9 $\mathrm{mmol} / \mathrm{L}$ in 4 months.

His LDL-C also responded significantly to the use of steroids. As the levels of his HDL-C decreased, the concentrations of LDL-C increased. His LDL-C increased to the highest levels of 6.5 and $5.8 \mathrm{mmol} / \mathrm{L}$ when his $\mathrm{HDL}-\mathrm{C}$ levels were at the lowest values of 0.2 and 0.1 $\mathrm{mmol} / \mathrm{L}$, respectively, a marked $\mathrm{LDL}-\mathrm{C}$ increase as compared with his normal value at 3.2-3.3 $\mathrm{mmol} / \mathrm{L}$. At the last visit, the levels of HDL-C as well as LDL-C were normalized after he stopped steroid use.

The biochemical mechanisms by which the anabolic steroids affect HDL-C and LDL-C concentrations are not completely understood. It is generally speculated that the induction of Hepatic Triglyceride Lipase (HTGL) activity and modification of apolipoprotein A-I and B synthesis play important roles in the alterations of HDL-C and LDL-C levels during the use of anabolic steroids. Anabolic steroids stimulate the activity of HTGL, an enzyme that facilities catabolism of HDL [2] and produces significant decreases of HDL-C and Apo-A-I concentrations $[11,12]$. However, the mechanism behind the adverse effect of anabolic steroid on increased LDL-C levels remains to be completely elucidated.

Management of this particular and interesting case involved education on the deleterious adverse effects of the anabolic steroids on the cardiovascular system, encouragement of stopping anabolic steroid use, as well as diet and aerobic exercise programs to improve his lipids. One of the reasons that the he repeatedly resumed the use the steroids was that he claimed he would suffer from the joint and skeletal muscle pain if he was not on steroids. If his pain can be controlled, a reasonable range of his lipids should be maintained without using the steroids. He was recommended to be reviewed by a rheumatologist or a chronic pain physician to manage these issues. In the end, his HDL-C and LDL-C were normalized after discontinuation of anabolic steroid.

This case demonstrates the profound effect that anabolic steroids can have on atherogenic lipid and lipoprotein particles. High LDL-C is universally accepted to be causally linked to atherosclerosis [13] and low HDL-C is a marker or risk factor for the development of cardiovascular disease [14]. The adverse effects of anabolic steroids on lipid levels may be one of the mechanisms underlying the correlation between anabolic steroids and the occurrence of acute myocardial infarction or stroke $[8,9]$. Most recently, a number of cross section-sectional studies have shown that the use of anabolic steroids are associated with impaired left ventricular systolic function [15], accelerated coronary atherosclerosis [16], increased thromboembolic risk [17], increased systolic blood pressure and aortic stiffness [18], and reduced insulin sensitivity [19] among anabolic steroids abusers. Users of anabolic steroids should be made aware of the cardiovascular risks and adverse effects on lipids that can play a role in producing atherosclerosis. Physicians should include anabolic steroid use in the differential diagnosis of causes of dyslipidemia. 


\section{Conflicts of Interest}

The authors disclose no conflicts of interest. There were no funding sources for this work.

\section{References}

1. Parkinson AB, Evans NA (2006) Anabolic androgenic steroids: a survey of 500 users. Med Sci Sports Exerc 38: 644-651.

2. Glazer G (1991) Atherogenic effects of anabolic steroids on serum lipid levels. A literature review. Arch Int Med 151: 1925-1933.

3. Thompson PD, Cullinane EM, Sady SP, Chenevert C, Saritelli AL, et al. (1989) Contrasting effects of testosterone and stanozolol on serum lipoprotein levels. JAMA 261 1165-1168.

4. Hartgens F, Rietjens G, Keizer HA, Kuipers H, Wolffenbuttel $\mathrm{BH}$ (2004) Effects of androgenic-anabolic steroids on apolipoproteins and lipoprotein (a). Br J Sports Med 38: 253-259.

5. Lenders J PN, Demacker P, Vos J, Jansen P, Hoitsma A, et al. (1988) Deleterious effects of anabolic steroids on serum lipoproteins, blood pressure, and liver function in amateur body builders. Int J Sports Med 9: 19-23.

6. Kuipers H, Wijnen JA, Hartgens F, Willems SM (1991) Influence of anabolic steroids on body composition, blood pressure, lipid profile and liver functions in body builders. Int J Sports Med 12: 413-418.

7. Vanberg P, Atar D (2010) Androgenic anabolic steroid abuse and the cardiovascular system. Handb Exp Pharmacol 411457.

8. Stergiopoulos K, Brennan JJ, Mathews R, Setaro JF, Kort $S$ (2008) Anabolic steroids, acute myocardial infarction and polycythemia: a case report and review of the literature. Vasc Health Risk Manag 4: 1475-1480.

9. Santamarina RD, Besocke AG, Romano LM, loli PL, Gonorazky SE (2008) Ischemic stroke related to anabolic abuse. Clin Neuropharmacol 31: 80-85.

10. Urhausen A, Torsten A, Wilfried K (2003) Reversibility of the effects on blood cells, lipids, liver function and hormones in former anabolic-androgenic steroid abusers. J Steroid Biochem Mol Biol 84: 369-375.

11. Kantor MA, Bianchini A, Bernier D, Sady SP, Thompson PD (1985) Androgens reduce HDL2-cholesterol and increase hepatic triglyceride lipase activity. Med Sci Sports Exerc 17: 462-465.

12. Applebaum-Bowden D, Haffner SM, Hazzard WR (1987) The dyslipoproteinemia of anabolic steroid therapy: increase in hepatic triglyceride lipase precedes the decrease in high density lipoprotein2 cholesterol. Metabolism 36: 949-952.

13. Ference BA, Ginsberg HN, Graham I, Ray KK, Packard CJ, et al. (2017) Low-density lipoproteins cause atherosclerotic cardiovascular disease. 1. Evidence from genetic, epidemiologic, and clinical studies. A consensus statement from the European Atherosclerosis Society Consensus Panel. Eur Heart J 38: 2459-2472.

14. Assmann G, Gotto AM Jr (2004) HDL cholesterol and protective factors in atherosclerosis. Circulation 109: 8-14.

15. Rasmussen JJ, Schou M, Madsen PL, Selmer C, Johansen $\mathrm{ML}$, et al. (2018) Cardiac systolic dysfunction in past illicit users of anabolic androgenic steroids. Am Heart J 203: 4956.

16. Baggish AL, Weiner RB, Kanayama G, Hudson JI, Lu MT, et al. (2017) Cardiovascular Toxicity of Illicit AnabolicAndrogenic Steroid Use. Circulation 135: 1991-2002.

17. Chang S, Rasmussen JJ, Frandsen MN, Schou M, Johansen ML, et al. (2018) Procoagulant State in Current and Former Anabolic Androgenic Steroid Abusers. Thromb Haemost 118: 647-653.

18. Rasmussen JJ, Schou M, Madsen PL, Selmer C, Johansen $\mathrm{ML}$, et al. (2018) Increased blood pressure and aortic stiffness among abusers of anabolic androgenic steroids: potential effect of suppressed natriuretic peptides in plasma? J Hypertens 36: 277-285.

19. Rasmussen JJ, Schou M, Selmer C, Johansen ML, Gustafsson F, et al. (2017) Insulin sensitivity in relation to fat distribution and plasma adipocytokines among abusers of anabolic androgenic steroids. Clin Endocrinol (Oxf) 87: 249-256. 